\title{
Tiotropium inhibits pulmonary inflammation and remodelling in a guinea pig model of COPD
}

\author{
T. Pera*, A. Zuidhof*, J. Valadas*, M. Smit*, R.G. Schoemaker", R. Gosens*, \\ H. Maarsingh*, J. Zaagsma* and H. Meurs*
}

ABSTRACT: Airway remodelling and emphysema are major structural abnormalities in chronic obstructive pulmonary disease (COPD). In addition, pulmonary vascular remodelling may occur and contribute to pulmonary hypertension, a comorbidity of COPD. Increased cholinergic activity in COPD contributes to airflow limitation and, possibly, to inflammation and airway remodelling.

This study aimed to investigate the role of acetylcholine in pulmonary inflammation and remodelling using an animal model of COPD. To this aim, guinea pigs were instilled intranasally with lipopolysaccharide (LPS) twice weekly for 12 weeks and were treated, by inhalation, with the long-acting muscarinic receptor antagonist tiotropium.

Repeated LPS exposure induced airway and parenchymal neutrophilia, and increased goblet cell numbers, lung hydroxyproline content, airway wall collagen and airspace size. Furthermore, LPS increased the number of muscularised microvessels in the adventitia of cartilaginous airways. Tiotropium abrogated the LPS-induced increase in neutrophils, goblet cells, collagen deposition and muscularised microvessels, but had no effect on emphysema.

In conclusion, tiotropium inhibits remodelling of the airways as well as pulmonary inflammation in a guinea pig model of COPD, suggesting that endogenous acetylcholine plays a major role in the pathogenesis of this disease.

KEYWORDS: Airway remodelling, emphysema, fibrosis, lipopolysaccharide, non-neuronal acetylcholine, pulmonary vascular remodelling

hronic obstructive pulmonary disease (COPD) is an inflammatory disease, characterised by a progressive decline in lung function and airflow limitation that is not fully reversible. Structural features of COPD, which contribute to the airflow limitation, include emphysema and airway remodelling, characterised by mucous cell hyperplasia and airway fibrosis [1]. In addition, pulmonary vascular remodelling has been observed, even in patients with mild COPD [2,3]. The remodelling of pulmonary vessels in COPD is characterised by smooth muscle proliferation, which contributes to thickening of the vessel wall of arteries $[4,5]$. Furthermore, there is evidence of muscularisation of small vessels, which do not have a smooth muscle layer under healthy conditions $[5,6]$. Although the mechanisms of tissue remodelling in COPD are largely unclear, chronic pulmonary inflammation, characterised by infiltration of neutrophils, macrophages, CD4and CD8-positive T-lymphocytes, and B-cells, is presumably of major importance [7].

Anticholinergics are indicated as bronchodilator therapy in COPD [8]. However, recent reports indicate that anticholinergics may have effects beyond bronchodilation. Thus, the recent UPLIFT study (Understanding Potential Long-term Impacts on Function with Tiotropium) [9-11] has shown that the use of the long-acting anticholinergic, tiotropium bromide, is associated with a reduction of the number of exacerbations, and of respiratory and cardiac morbidity and mortality of COPD patients $[9,10]$. In addition, pre-specified subgroup analyses of the UPLIFT study have indicated protective effects of tiotropium on postbronchodilator forced expiratory volume in $1 \mathrm{~s}$ (FEV1) decline in Global Initiative for Chronic Obstructive Lung Disease (GOLD) stage II COPD patients [11].

\section{AFFILIATIONS}

${ }^{*}$ Dept of Molecular Pharmacology, University Centre for Pharmacy, University of Groningen, and \#Dept of Cardiology, University Medical Centre Groningen, Groningen, The Netherlands.

\section{CORRESPONDENCE}

T. Pera

Dept of Molecular Pharmacology University Centre for Pharmacy Antonius Deusinglaan 1 9713 AV

Groningen

The Netherlands

E-mail: t.pera@rug.nl

Received:

Sept 152010

Accepted after revision:

Feb 092011

First published online: Feb 242011 
The airways are primarily innervated by parasympathetic cholinergic neurons, which regulate airway smooth muscle (ASM) contraction and mucus secretion [12-14]. Bronchomotor tone is increased in COPD, probably due to increased neuronal release of acetylcholine (ACh), which is the major reversible component of airflow obstruction in this disease [8, 12]. Accumulating evidence suggests that in addition to neuronal ACh, non-neuronal ACh may also play a role in the pathogenesis of COPD [12]. Thus, the ACh-synthesising enzyme choline acetyltransferase (ChAT), as well as muscarinic receptors, are expressed in both structural and inflammatory cells in the lung [12]. Remarkably, increased ChAT expression was found in lung fibroblasts from smokers and COPD patients [15]. Muscarinic $\mathrm{M}_{3}$ receptor stimulation has been shown to increase the release of neutrophil chemotactic activity by alveolar macrophages [16], induce interleukin (IL)-8 release by bronchial epithelial cells [17] and monocytes [18], and augment cigarette smoke-induced IL- 8 release by ASM cells [19]. In addition, muscarinic receptor agonists were shown to stimulate or potentiate proliferation of lung fibroblasts [20] and ASM cells [21], as well as lung fibroblast collagen synthesis [22]. Collectively, these data suggest a proinflammatory and pro-remodelling modulatory role for ACh in the lung. Evidence for such a role has also been found in a guinea pig model of chronic allergic asthma. In this model, it was demonstrated that tiotropium reduces airway eosinophilia, as well as ASM remodelling and goblet cell hyperplasia, upon repeated allergen exposure [23, 24]. In addition, tiotropium has recently been shown to inhibit airway inflammation and remodelling in a mouse model of gastrooesophageal reflux disease [25].

Currently, the role of $\mathrm{ACh}$ in the development and progression of COPD is unknown. In the present study, we addressed this question using a guinea pig model of lipopolysaccharide (LPS)induced COPD. LPS is a component of the outer wall of Gram-negative bacteria, and a contaminant of organic dusts, environmental pollution and tobacco smoke [26], and has been associated with the development of COPD [27]. In addition, LPS may play an important role in bacterial infection-induced exacerbations of COPD, which contribute to the progression of the disease [28]. Accordingly, in various animal models, inhalation of LPS was shown to induce pathological features of COPD, such as neutrophilia, goblet cell hyperplasia, airway fibrosis and emphysema [29-32]. In the present study, we present evidence that ACh plays a major role in the development of pulmonary inflammation as well as in airway remodelling.

\section{METHODS}

\section{Animals}

Outbred, male, specified pathogen-free Dunkin Hartley guinea pigs (Harlan, Heathfield, UK) weighing 350-400 g were used. All protocols described in this study were approved by the University of Groningen Committee for Animal Experimentation, Groningen, the Netherlands.

\section{LPS instillation}

Conscious guinea pigs were held in an upright position, while

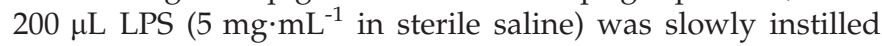
intranasally. After the intranasally instilled solution was aspirated, the animals were kept in the upright position for an additional 2 min to allow sufficient spreading of the fluid throughout the airways. Control animals were instilled with $200 \mu \mathrm{L}$ sterile saline.

\section{Experimental protocol}

Guinea pigs were challenged by intranasal instillation with either LPS or saline twice weekly, for 12 consecutive weeks. $30 \mathrm{~min}$ prior to each instillation, animals received a nebulised dose of tiotropium bromide (Boehringer Ingelheim, Ingelheim, Germany) in saline (0.1 $\mathrm{mM}$ for $3 \mathrm{~min}$ ) or saline (3 $\mathrm{min})$, using a DeVilbiss nebulizer (type 646; DeVilbiss Healthcare, Somerset, PA, USA) as described previously [33]. This dose of tiotropium has previously been shown to induce protection against inhaled methacholine that was measurable for $\sim 96 \mathrm{~h}$ [34]. $24 \mathrm{~h}$ after the last instillation, the guinea pigs were sacrificed by experimental concussion followed by rapid exsanguination. The lungs were immediately resected and kept on ice for further processing.

\section{Tissue analysis}

Transverse frozen cross-sections $(4 \mu \mathrm{m})$ of the middle right lung lobe were used for histological and immunohistochemical analyses. To identify smooth muscle and goblet cells, sections were stained for smooth muscle myosin heavy chain (smMHC) or MUC5AC, respectively, as described previously [24]. Neutrophils were identified by staining sections for TNAP (tissue nonspecific alkaline phosphatase activity) [35]. For immunohistochemical stainings, primary antibodies (all from Neomarkers, Fremont, CA, USA) were visualised using horseradish peroxidase-linked secondary antibodies (Sigma, St Louis, MO, USA), diaminobenzidine $\left(0.3 \mathrm{mg} \cdot \mathrm{mL}^{-1}\right)$ and ammonium nickel sulphate $\left(25 \mathrm{mg} \cdot \mathrm{mL}^{-1}\right)$, adapted from ADAMS [36]. Sections were counterstained with haematoxylin. Airways within sections were digitally photographed and classified as cartilaginous or noncartilaginous. All immunohistochemical measurements were carried out digitally using quantification software (ImageJ; National Institutes for Health, Bethesda, MD, USA; http://rsb.info.nih.gov/ij/). For this purpose, the digital photographs were analysed at a magnification of $40-400 \times$. For each animal, two lung sections were prepared per staining, in which a total of 2-6 airways of each classification were analysed. Airway neutrophils were counted in the adventitia and sub-mucosa, and expressed as the number of positively stained cells per millimetre basement membrane length. For parenchymal neutrophil counts, positively stained cells were counted in five random microscopic fields using an eyepiece graticule and expressed as a percentage of total cell counts. MUC5AC-positive cells were counted in the epithelial layer and expressed as number of cells per millimetre basement membrane length. Microvessels that stained positively for sm-MHC were counted in the adventitia of cartilaginous airways and were expressed as number of vessels per square millimetre adventitia.

The upper right lung lobe was removed, inflated and fixed with formalin at a constant pressure of $25 \mathrm{cmH}_{2} \mathrm{O}$ for $24 \mathrm{~h}$, and embedded in paraffin. $4-\mu \mathrm{m}$ thick paraffin sections were cut. For evaluation of emphysema, paraffin sections were stained with haematoxylin and eosin. The mean linear intercept (MLI) was determined as a measure of alveolar airspace size, using 20-25 photomicroscopic images (magnification $200 \times$ ) per 
animal, as described previously [37]. For evaluation of airway wall collagen, paraffin sections were stained with Sirius Red and counterstained with haematoxylin. Noncartilaginous airways were digitally photographed (magnification 100-200× ) and the individual colour images were split into the red, green and blue channels. Using Image J, the black and white images from the green channel were converted to binary images using the threshold function. The positively stained area in the airway wall, from the adventitial border to the basement membrane, was determined in 2-6 airways of each animal. The airway wall collagen area was normalised to the square of the basement membrane length. For evaluation of pulmonary vascular remodelling, paraffin sections were stained with Weigert's elastin (resorcin/fuchsin) and Van Gieson stain. The measurements were performed according to VAN SUYLEN et al. [38]. Total vessel area of pulmonary arteries was defined as the area within the lamina elastica externa, and lumen area was defined as the area within the lamina elastica interna. Medial area is the area between the lamina elastica interna and the lamina elastica externa. The medial area was normalised to the lumen area. Pulmonary arteries with an external diameter of 30-100 $\mu \mathrm{m}$ were analysed. The wall area of pulmonary arterioles was defined as the area between the lamina elastica externa and the lumen, and was normalised to the lumen area. Only vessels with the longest/shortest diameter ratio $<2$ were analysed.

\section{Hydroxyproline assay}

Lungs were analysed for hydroxyproline as an estimate of collagen content [39], as described previously [40]. Lung homogenates were prepared by pulverising tissue under liquid nitrogen, followed by sonification in PBS. Subsequently, homogenates were incubated with $5 \% \mathrm{v} / \mathrm{v}$ trichloroacetic acid on ice for $20 \mathrm{~min}$. Samples were centrifuged and the pellet was resuspended in $10 \mathrm{~mL}$ of $12 \mathrm{~N}$ hydrochloric acid and heated overnight at $110^{\circ} \mathrm{C}$. The samples were reconstituted in $2 \mathrm{~mL}$ water by incubating for $72 \mathrm{~h}$ at room temperature, applying intermittent vortexing. $5-\mu \mathrm{L}$ samples were incubated with
$100 \mu \mathrm{L}$ chloramine $\mathrm{T}(1.4 \%$ chloramine $\mathrm{T}$ in $0.5 \mathrm{M}$ sodium acetate $/ 10 \%$ isopropanol) in a 96 -well plate, for $30 \mathrm{~min}$ at room temperature. Next, $100 \mu \mathrm{L}$ Ehrlich's solution (1.0 M 4-dimethylaminobenzaldehyde in $70 \%$ isopropanol $/ 30 \%$ perchloric acid) was added and samples were incubated at $65^{\circ} \mathrm{C}$ for $30 \mathrm{~min}$. Samples were cooled to room temperature and the amount of hydroxyproline was quantified by colorimetric measurement (550 nm; Biorad 680 plate reader; Biorad, Hercules, CA, USA) of a pyrrole derivative of hydroxyproline, which forms a chromophore with Erlich's reagent. Concentrations were calculated using a standard curve. Data are expressed as milligrammes of hydroxyproline per lung.

\section{Statistical analysis}

Data are presented as mean \pm SEM. Unless otherwise specified, statistical differences between means were calculated using one-way ANOVA, followed by Boniferroni or Newman-Keuls multiple comparison test, as appropriate. Differences were considered significant at $\mathrm{p}<0.05$

\section{RESULTS}

\section{Inflammation}

The neutrophil is a major inflammatory cell involved in the pathogenesis of COPD. Repeated LPS instillation induced significant increases in the numbers of neutrophils in both cartilaginous (2.0-fold) and noncartilaginous (1.9-fold) airways as well as in the parenchyma (2.1-fold) (fig. 1). Tiotropium treatment fully inhibited the LPS-induced neutrophilia in these compartments. Neutrophil numbers were not affected by tiotropium in the airways or the parenchyma of salinechallenged animals. These data indicate that tiotropium has a profound anti-inflammatory activity in chronically LPSinstilled guinea pigs.

\section{MUC5AC expression}

In order to investigate the effects of LPS and tiotropium on mucus-producing goblet cells, sections were stained with a
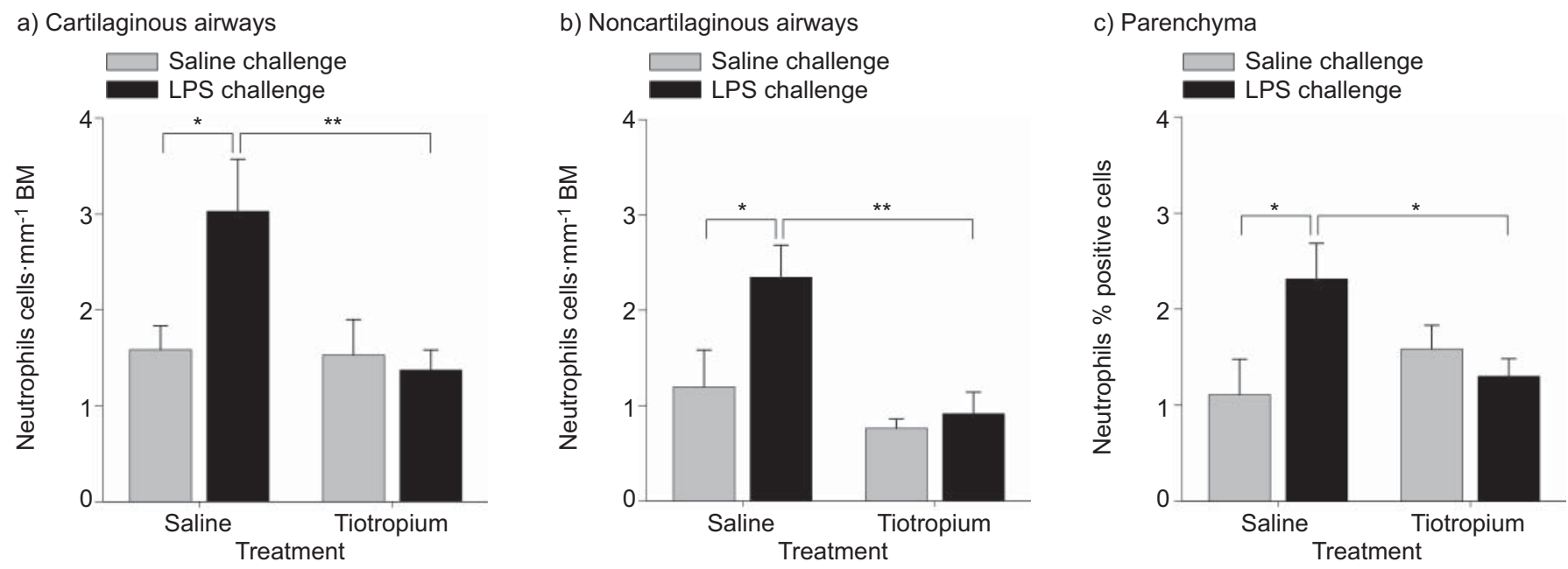

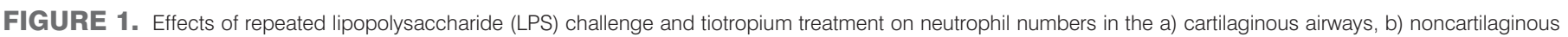

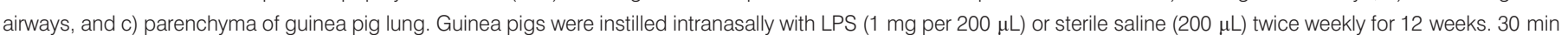

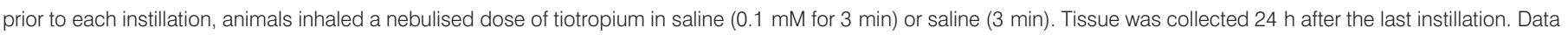

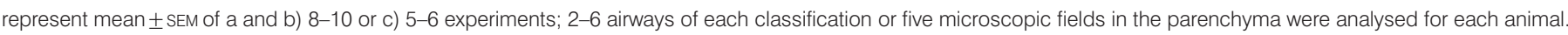
BM: basement membrane. *: $p<0.05$; ${ }^{*}: \mathrm{p}<0.01$. 


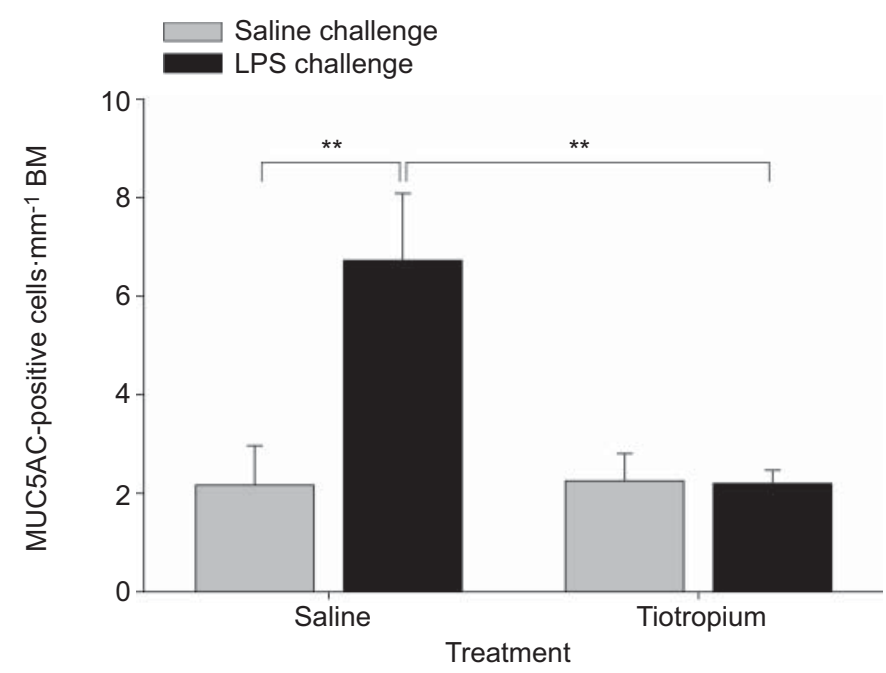

FIGURE 2. Effects of repeated lipopolysaccharide (LPS) challenge and tiotropium treatment on MUC5AC-positive goblet cell number in guinea pig intrapulmonary cartilaginous airways. Guinea pigs were instilled intranasally with LPS (1 mg per $200 \mu \mathrm{L})$ or sterile saline $(200 \mu \mathrm{L})$ twice weekly for 12 weeks. 30 min prior to each instillation, animals inhaled a nebulised dose of tiotropium in saline $(0.1 \mathrm{mM}, 3 \mathrm{~min})$ or saline $(3 \mathrm{~min})$. Tissue was collected $24 \mathrm{~h}$ after the last instillation. Data represent mean \pm SEM of seven experiments; $2-5$ airways were analysed for each animal. BM: basement membrane. ${ }^{*}$ : $p<0.01$.

MUC5AC antibody. Repeated LPS instillation induced a significant 3.1-fold increase in the number of MUC5ACpositive cells in the epithelium of cartilaginous airways of the guinea pigs (fig. 2). Tiotropium treatment fully inhibited the LPS-induced increase, whereas it had no effect in salinechallenged animals.

a) Whole lung hydroxyproline

$\square$ Saline challenge

LPS challenge

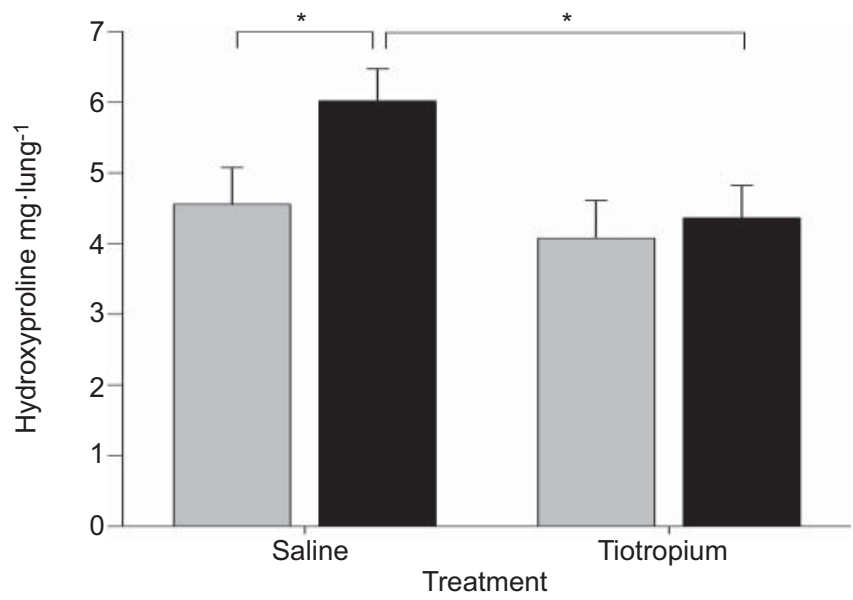

\section{Airway fibrosis}

To evaluate fibrotic changes, lungs were analysed for hydroxyproline as an estimate of collagen content. Repeated LPS instillation induced a significant 1.3-fold increase in total lung hydroxyproline content (fig. 3). To confirm that collagen deposition was indeed increased in the airway compartment, Sirius Red staining was evaluated in the airway wall of noncartilaginous airways. LPS induced a 1.7-fold increase in airway wall collagen content. Tiotropium fully inhibited the increase in hydroxyproline and airway wall collagen deposition induced by repeated LPS instillation, whereas it had no effect in saline-challenged animals.

\section{Emphysema}

In order to evaluate the alveolar airspace size, MLI was determined in paraffin-embedded lung sections. A $7.3 \%$ increase in MLI was observed after 12 weeks of twice-weekly LPS instillations (fig. 4). Tiotropium had no effect on the airspace size in either LPS- or saline-instilled animals.

\section{Vascular remodelling}

To evaluate pulmonary vascular remodelling, pulmonary artery medial area and pulmonary arteriole wall area were determined in formalin-fixed, paraffin-embedded guinea pig lung sections stained with Weigert's elastin and Van Gieson stain. Neither repeated LPS instillation nor tiotropium treatment had an effect on the medial area of pulmonary arteries or wall area of pulmonary arterioles (fig. 5). In addition, there was no evidence of intimal proliferation in the pulmonary vessels of either classification. However, repeated LPS instillation increased the number of muscularised (sm-MHC-positive) microvessels in the adventitia of cartilaginous airways (2.4fold) (fig. 6). This increase was fully inhibited by tiotropium.

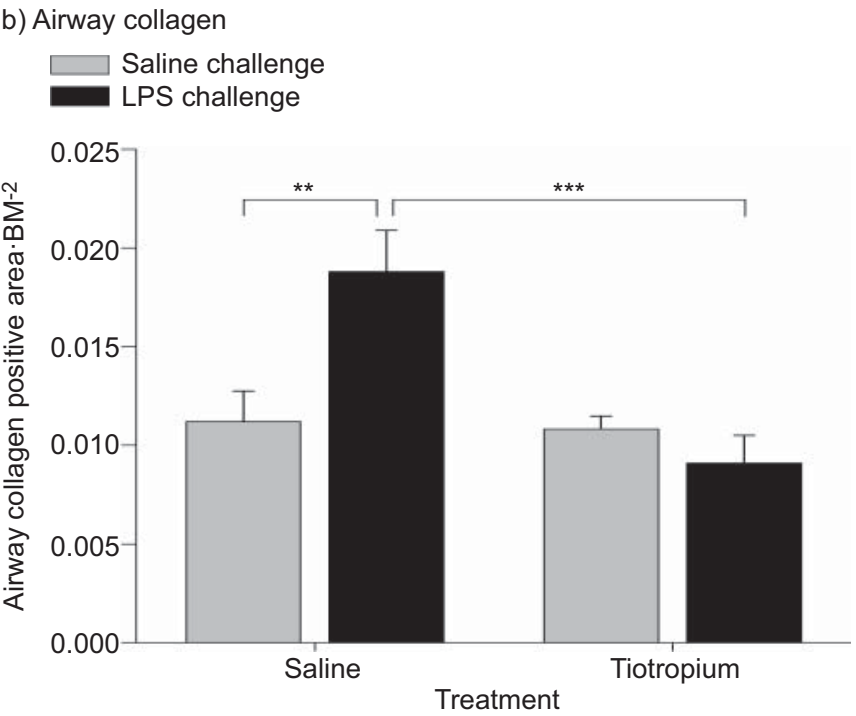

FIGURE 3. Effects of repeated lipopolysaccharide (LPS) challenge and tiotropium treatment on guinea pig a) whole lung hydroxyproline content and b) collagen content in noncartilaginous airways. Guinea pigs were instilled intranasally with LPS (1 mg per $200 \mu \mathrm{L})$ or sterile saline $(200 \mu \mathrm{L})$ twice weekly for 12 weeks. 30 min prior to each instillation, animals inhaled a nebulised dose of tiotropium in saline $(0.1 \mathrm{mM}, 3 \mathrm{~min})$ or saline ( $3 \mathrm{~min})$. Tissue was collected $24 \mathrm{~h}$ after the last instillation. b) Airway wall collagen was determined as Sirius Red-positive area and normalised to the square of the basement membrane length (BM ${ }^{2}$ ). Data represent mean \pm SEM of a) $10-12$ or b) $5-6$ experiments; b) 2-6 airways were analysed for each animal. ${ }^{*}$ : $p<0.05 ;{ }^{* *}: p<0.01 ;{ }^{* *}: p<0.001$. 


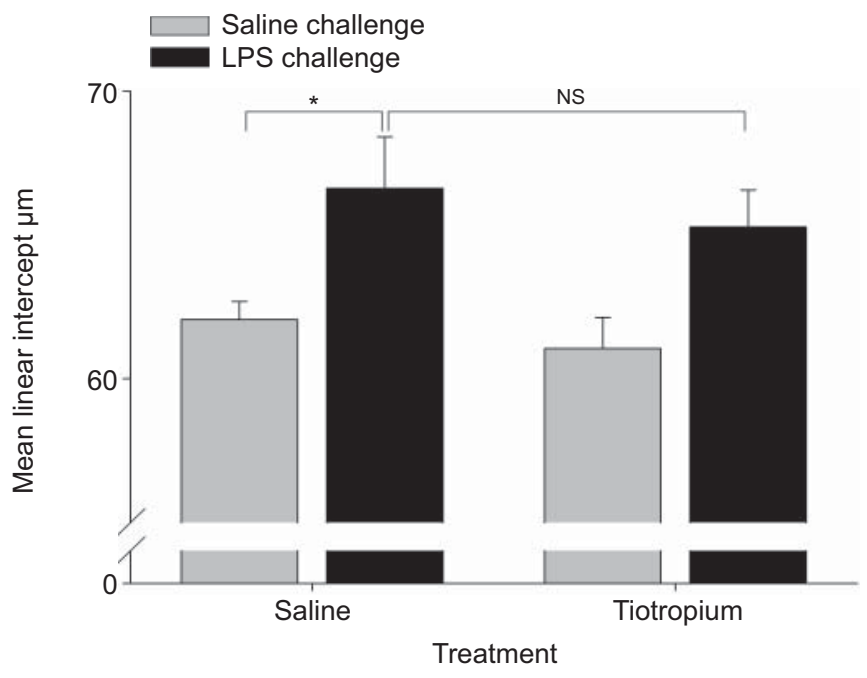

FIGURE 4. Effects of repeated lipopolysaccharide (LPS) challenge and tiotropium treatment on alveolar airspace size (mean linear intercept) in guinea pig lung. Guinea pigs were instilled intranasally with LPS (1 mg per $200 \mu \mathrm{L}$ ) or sterile saline $(200 \mu \mathrm{L})$ twice weekly for 12 weeks. 30 min prior to each instillation, animals inhaled a nebulised dose of tiotropium in saline $(0.1 \mathrm{mM}, 3 \mathrm{~min})$ or saline ( $3 \mathrm{~min}$ ). Tissue was collected $24 \mathrm{~h}$ after the last instillation. Data represent mean \pm SEM of $4-5$ experiments. *: $p<0.05$; NS: not significant.

\section{DISCUSSION}

In this study, we demonstrate for the first time that tiotropium inhalation inhibits neutrophilia, MUC5AC expression and airway fibrosis in an animal model of COPD induced by repeated LPS exposure. In addition, we showed that repeated LPS instillation induced remodelling of the adventitial airway vasculature in this model, which was inhibited by tiotropium. Collectively, these data suggest that endogenous ACh, acting through muscarinic receptors, plays a major role in pulmonary inflammation as well as in airway remodelling in COPD.
Neutrophil numbers are increased in sputum and bronchoalveolar lavage fluid of COPD patients [41]. In addition, correlation between COPD severity and neutrophil numbers in the large airways and the percentage of neutrophil-containing small airways has been reported [41]. ACh may contribute to neutrophilia as it was shown to stimulate the release of neutrophil chemotactic activity from isolated alveolar macrophages [16] and from isolated sputum cells of COPD patients [42]. Furthermore, activation of muscarinic receptors expressed in airway structural cells, including bronchial epithelial [17] and ASM cells [19], may also contribute to neutrophil sequestration in the lungs by inducing or augmenting IL-8 release by these cells. In addition, the high capacity of neutrophils to synthesise ACh [43] implies that neutrophilia may result in increased non-neuronal ACh release in the lung. In our study, repeated LPS exposure increased neutrophil numbers in the airways and in the parenchyma. Because tiotropium inhalation fully inhibited this LPS-induced neutrophilic inflammation, a major role for ACh is inferred.

Mucus hypersecretion is a characteristic feature of COPD that contributes significantly to airflow obstruction. MUC5AC expression can be upregulated by a variety of stimuli, including cigarette smoke, LPS and neutrophil elastase, and is increased in the airway epithelium of COPD patients [44]. The present study indicates that endogenous ACh also plays a crucial role in LPS-induced MUC5AC expression. Interestingly, as early as in 1973, goblet cell hyperplasia has been observed following repeated administration of muscarinic agonists in experimental animals [45].

Airway fibrosis contributes to small airway thickening and airflow limitation in COPD [46]. The role of ACh in airway fibrosis in COPD is currently unknown. However, in vitro studies have indicated that ACh can induce proliferation of lung fibroblasts [20], and collagen synthesis by these cells [22]. In addition, increased ChAT expression has recently been found in lung fibroblasts from healthy smokers and from COPD patients [15], suggesting that non-neuronal ACh may a) Pulmonary arteries

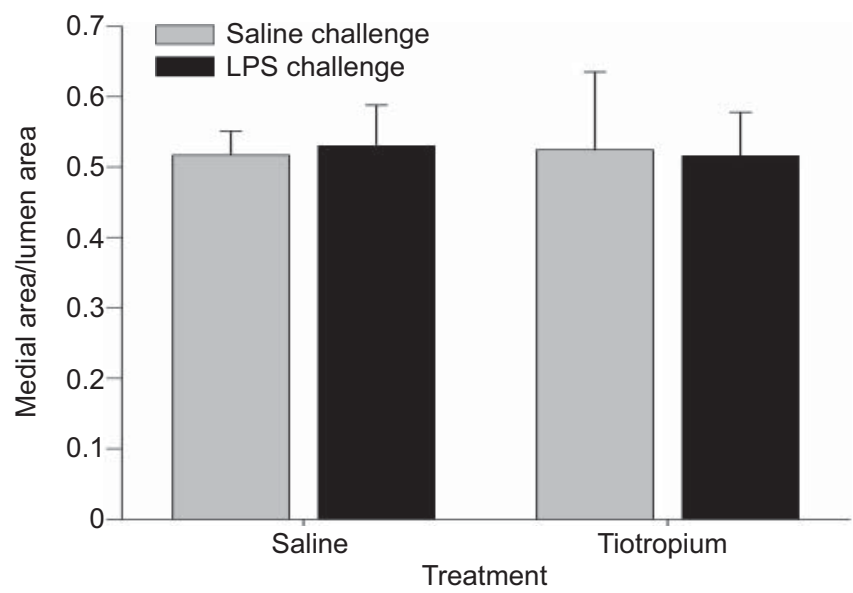

b) Pulmonary arterioles

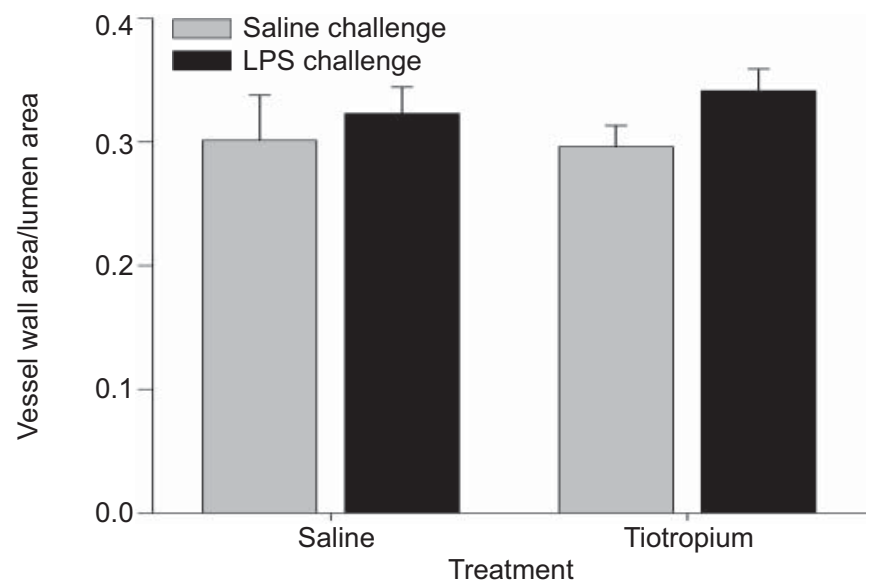

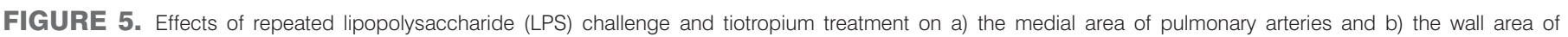

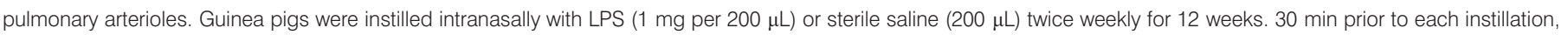

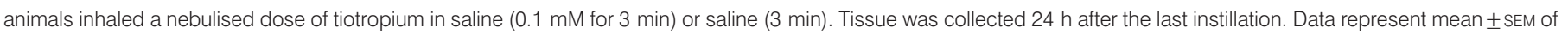
6-8 experiments. 


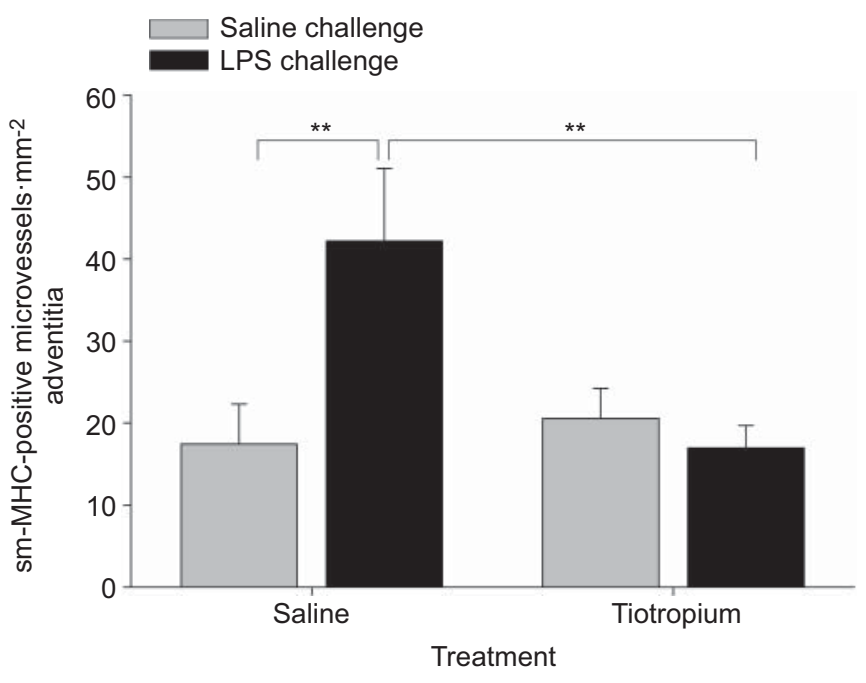

FIGURE 6. Effects of repeated lipopolysaccharide (LPS) challenge and tiotropium treatment on the number of muscularised microvessels in the airway adventitia of cartilaginous airways in guinea pig lung. Guinea pigs were instilled intranasally with LPS (1 mg per $200 \mu \mathrm{L})$ or sterile saline (200 $\mu \mathrm{L})$ twice weekly for 12 weeks. 30 min prior to each instillation, animals inhaled a nebulised dose of tiotropium in saline ( $0.1 \mathrm{mM}$ for $3 \mathrm{~min}$ ) or saline ( $3 \mathrm{~min}$ ). Tissue was collected $24 \mathrm{~h}$ after the last instillation. Data represent mean \pm SEM of 7-9 experiments. SM-MHC: smooth muscle myosin heavy chain. **: $p<0.01$.

modulate fibroblast function in an autocrine fashion under these conditions. Our results demonstrated that tiotropium inhibits LPS-induced collagen accumulation in the lung and airway wall, indicating that ACh may be a key regulator of airway fibrosis. In addition to a possible direct effect of ACh on fibroblasts in this process, its effect on neutrophils could also play a role. Thus, increased neutrophil elastase activity, as observed in COPD [41], has also been associated with pulmonary fibrotic diseases, such as idiopathic pulmonary fibrosis [47]. The potential role of neutrophil elastase in fibrosis is further supported by studies in mice, showing that neutrophil elastase inhibition [48] or gene deletion [49] inhibits bleomycin-induced pulmonary fibrosis in these animals.

LPS induced a significant increase in alveolar airspace size, which is indicative of emphysema. The observed increase in MLI after 12 weeks of twice-weekly LPS instillation is of a similar magnitude to that described previously for mice following 16 weeks exposure to cigarette smoke [37]. In our study, no evidence for the involvement of ACh in the development of LPS-induced emphysema was found. Thus, tiotropium had no significant effect on airspace size in either LPS- or saline-instilled animals. This could imply that neutrophilic inflammation is not essential for the development of LPS-induced emphysema, which corresponds with previous observations in patients with COPD [41]. The mechanisms leading to the development of LPS-induced emphysema are not entirely clear, but presumably the release of elastolytic enzymes from neutrophils plays a role. Although chronic LPSinduced parenchymal neutrophilia in our model was inhibited by tiotropium, this does not necessarily mean that neutrophils have not contributed to alveolar destruction. A recent study in mice has shown that the acute LPS-induced bronchoalveolar lavage neutrophilia (at $4 \mathrm{~h}$ post-LPS exposure) is not affected by tiotropium pre-treatment [50]. This finding indicates that tiotropium does not inhibit the acute LPS-induced signalling, which leads to the release of neutrophil-attracting chemokines, resulting in acute neutrophilia. Since a brief exposure to neutrophil elastase may already lead to emphysema, the acute tiotropium-resistant neutrophilic response after each LPS instillation could be sufficient to initiate the development of emphysema. In addition, other inflammatory cell types, such as macrophages, CD8-positive T-lymphocytes and B-cells, may also contribute $[37,41]$.

Pulmonary vascular remodelling may occur in patients with COPD and contribute to pulmonary hypertension in these patients [51]. Pulmonary vascular remodelling in COPD is characterised by thickening of the vessel wall as well as muscularisation of microvessels that do not have a smooth muscle layer under healthy conditions [4, 6]. The precise mechanisms underlying the pulmonary vascular remodelling in COPD are not known, but may involve hypoxia, inflammation and cigarette smoke constituents, leading to endothelial dysfunction and release of growth factors [52]. The increase in vessel wall thickness is largely due to smooth muscle cell proliferation in the intima [4] as well as thickening of the media [6]. Interestingly, thickening of pulmonary arteries and increased number of small vessels positive for smooth muscle actin have been found in guinea pigs after 3 or 6 months exposure to cigarette smoke [53]. In contrast, in the present study, no effect of LPS on pulmonary artery or arteriole thickness was found. Similarly, LPS did not affect ASM mass under the same conditions (data not shown). However, LPS did increase the number of muscularised microvessels in the adventitia of cartilaginous airways. The strong inhibitory effect of tiotropium on this increase indicates a major role for endogenous $\mathrm{ACh}$ in this process. Although the mechanisms underlying these changes are presently unknown, airway inflammation might play a role [54]. This is supported by the observation that the neutrophil infiltration and its inhibition by tiotropium is particularly observed in the adventitial compartment of the airways (data not shown).

Recently, results of the UPLIFT trial have demonstrated that tiotropium treatment of patients with COPD reduces the number of exacerbations, the incidence of respiratory and cardiac adverse events as well as mortality [9, 10]. A prespecified subgroup analysis also showed that in GOLD stage II COPD, tiotropium treatment reduces the rate of decline of post-bronchodilator FEV1 [11]. Although the mechanisms underlying these effects remain to be established, data from our animal model suggest that anti-inflammatory and antiremodelling properties of the drug could be involved.

In conclusion, our study has demonstrated that inhaled tiotropium inhibits pulmonary inflammation and airway remodelling in a guinea pig model of COPD, indicating that endogenous ACh may play a major role in the pathogenesis of this disease.

\section{SUPPORT STATEMENT}

This study was financially supported by Boehringer Ingelheim Pharma $\mathrm{GmbH} \& \mathrm{Co} . \mathrm{KG}$, and the Graduate School of Behavioural and Cognitive Neurosciences, University of Groningen, Groningen, the Netherlands. 


\section{STATEMENT OF INTEREST}

Statements of interest for R. Gosens, J. Zaagsma, and H. Meurs, and for the study itself can be found at www.erj.ersjournals.com/site/misc/ statements.xhtml

\section{REFERENCES}

1 Pauwels RA, Buist AS, Calverley PM, et al. Global strategy for the diagnosis, management, and prevention of chronic obstructive pulmonary disease. NHLBI/WHO Global Initiative for Chronic Obstructive Lung Disease (GOLD) Workshop summary. Am J Respir Crit Care Med 2001; 163: 1256-1276.

2 Peinado VI, Barbera JA, Abate P, et al. Inflammatory reaction in pulmonary muscular arteries of patients with mild chronic obstructive pulmonary disease. Am J Respir Crit Care Med 1999; 159: 1605-1611.

3 Wright JL, Lawson L, Pare PD, et al. The structure and function of the pulmonary vasculature in mild chronic obstructive pulmonary disease. The effect of oxygen and exercise. Am Rev Respir Dis 1983; 128: 702-707.

4 Santos S, Peinado VI, Ramírez J, et al. Characterization of pulmonary vascular remodelling in smokers and patients with mild COPD. Eur Respir J 2002; 19: 632-638.

5 Shelton DM, Keal E, Reid L. The pulmonary circulation in chronic bronchitis and emphysema. Chest 1977; 71: 303-306.

6 Wright JL, Petty T, Thurlbeck WM. Analysis of the structure of the muscular pulmonary arteries in patients with pulmonary hypertension and COPD: National Institutes of Health nocturnal oxygen therapy trial. Lung 1992; 170: 109-124.

7 Hogg JC, Timens W. The pathology of chronic obstructive pulmonary disease. Annu Rev Pathol 2009; 4: 435-459.

8 Gross NJ, Skorodin MS. Role of the parasympathetic system in airway obstruction due to emphysema. N Engl J Med 1984; 311: 421-425.

9 Tashkin DP, Celli B, Senn S, et al. A 4-year trial of tiotropium in chronic obstructive pulmonary disease. $N$ Engl J Med 2008; 359: 1543-1554.

10 Celli B, Decramer M, Kesten S, et al. Mortality in the 4 year trial of tiotropium (UPLIFT) in patients with COPD. Am J Respir Crit Care Med 2009; 180: 948-955.

11 Decramer M, Celli B, Kesten S, et al. Effect of tiotropium on outcomes in patients with moderate chronic obstructive pulmonary disease (UPLIFT): a prespecified subgroup analysis of a randomised controlled trial. Lancet 2009; 374: 1171-1178.

12 Gosens R, Zaagsma J, Meurs H, et al. Muscarinic receptor signaling in the pathophysiology of asthma and COPD. Respir Res 2006; 7: 73.

13 Rogers DF. Motor control of airway goblet cells and glands. Respir Physiol 2001; 125: 129-144.

14 Zaagsma J, Roffel AF, Meurs H. Muscarinic control of airway function. Life Sci 1997; 60: 1061-1068.

15 Profita M, Bonanno A, Siena L, et al. Smoke, choline acetyltransferase, muscarinic receptors, and fibroblast proliferation in chronic obstructive pulmonary disease. J Pharmacol Exp Ther 2009; 329: 753-763.

16 Sato E, Koyama S, Okubo Y, et al. Acetylcholine stimulates alveolar macrophages to release inflammatory cell chemotactic activity. Am J Physiol 1998; 274: L970-L979.

17 Profita M, Bonanno A, Siena L, et al. Acetylcholine mediates the release of IL-8 in human bronchial epithelial cells by a NFкB/ERKdependent mechanism. Eur J Pharmacol 2008; 582: 145-153.

18 Buhling F, Lieder N, Kuhlmann UC, et al. Tiotropium suppresses acetylcholine-induced release of chemotactic mediators in vitro. Respir Med 2007; 101: 2386-2394.

19 Gosens R, Rieks D, Meurs H, et al. Muscarinic M3 receptor stimulation increases cigarette smoke-induced IL-8 secretion by human airway smooth muscle cells. Eur Respir J 2009; 34: 1436-1443.
20 Matthiesen S, Bahulayan A, Kempkens S, et al. Muscarinic receptors mediate stimulation of human lung fibroblast proliferation. Am J Respir Cell Mol Biol 2006; 35: 621-627.

21 Gosens R, Dueck G, Rector E, et al. Cooperative regulation of GSK-3 by muscarinic and PDGF receptors is associated with airway myocyte proliferation. Am J Physiol Lung Cell Mol Physiol 2007; 293: L1348-L1358.

22 Haag S, Matthiesen S, Juergens UR, et al. Muscarinic receptors mediate stimulation of collagen synthesis in human lung fibroblasts. Eur Respir J 2008; 32: 555-562.

23 Gosens R, Bos IS, Zaagsma J, et al. Protective effects of tiotropium bromide in the progression of airway smooth muscle remodeling. Am I Respir Crit Care Med 2005; 171: 1096-1102.

24 Bos IST, Gosens R, Zuidhof $\mathrm{AB}$, et al. Inhibition of allergeninduced airway remodelling by tiotropium and budesonide: a comparison. Eur Respir J 2007; 30: 653-661.

25 Cui Y, Devillier P, Kuang X, et al. Tiotropium reduction of lung inflammation in a model of chronic gastro-oesophageal reflux. Eur Respir J 2010; 35: 1370-1376.

26 Rylander R. Endotoxin and occupational airway disease. Curr Opin Allergy Clin Immunol 2006; 6: 62-66.

27 Eduard W, Pearce N, Douwes J. Chronic bronchitis, COPD, and lung function in farmers: the role of biological agents. Chest 2009; 136: 716-725

28 Patel IS, Seemungal TA, Wilks M, et al. Relationship between bacterial colonisation and the frequency, character, and severity of COPD exacerbations. Thorax 2002; 57: 759-764.

29 Brass DM, Hollingsworth JW, Cinque M, et al. Chronic LPS inhalation causes emphysema-like changes in mouse lung that are associated with apoptosis. Am J Respir Cell Mol Biol 2008; 39: 584-590.

30 Savov JD, Brass DM, Lawson BL, et al. Toll-like receptor 4 antagonist (E5564) prevents the chronic airway response to inhaled lipopolysaccharide. Am J Physiol Lung Cell Mol Physiol 2005; 289: L329-L337.

31 Toward TJ, Broadley KJ. Goblet cell hyperplasia, airway function, and leukocyte infiltration after chronic lipopolysaccharide exposure in conscious guinea pigs: effects of rolipram and dexamethasone. J Pharmacol Exp Ther 2002; 302: 814-821.

32 Vernooy JH, Dentener MA, van Suylen RJ, et al. Long-term intratracheal lipopolysaccharide exposure in mice results in chronic lung inflammation and persistent pathology. Am J Respir Cell Mol Biol 2002; 26: 152-159.

33 Meurs H, Santing RE, Remie R, et al. A guinea pig model of acute and chronic asthma using permanently instrumented and unrestrained animals. Nat Protoc 2006; 1: 840-847.

34 Roffel AF, Meurs H, Zaagsma J. Muscarinic receptors and the lung relevance to chronic obstructive pulmonary disease and asthma. In Barnes PJ, Buist AS, eds. The Role of Anticholinergics in Chronic Obstructive Pulmonary Disease and Chronic Asthma. 1st Edn. Macclesfield, Gardiner-Caldwell Communications, 1997; pp. 92-125.

35 Westerhof F, Timens W, van OA, et al. Inflammatory cell distribution in guinea pig airways and its relationship to airway reactivity. Mediators Inflamm 2001; 10: 143-154.

36 Adams JC. Heavy metal intensification of DAB-based HRP reaction product. J Histochem Cytochem 1981; 29: 775.

37 van der Strate BW, Postma DS, Brandsma CA, et al. Cigarette smoke-induced emphysema: a role for the B cell? Am J Respir Crit Care Med 2006; 173: 751-758.

38 van Suylen RJ, Smits JF, Daemen MJ. Pulmonary artery remodeling differs in hypoxia- and monocrotaline-induced pulmonary hypertension. Am J Respir Crit Care Med 1998; 157: 1423-1428.

39 Woessner JF. The determination of hydroxyproline in tissue and protein samples containing small proportions of this imino acid Arch Biochem Biophys 1961; 93: 440-447.

40 Dekkers BG, Bos IS, Gosens R, et al. The integrin-blocking peptide RGDS inhibits airway smooth muscle remodeling in a guinea pig model of allergic asthma. Am J Respir Crit Care Med 2010; 181: 556-565. 
41 Tetley TD. Inflammatory cells and chronic obstructive pulmonary disease. Curr Drug Targets Inflamm Allergy 2005; 4: 607-618.

42 Profita M, Giorgi RD, Sala A, et al. Muscarinic receptors, leukotriene B4 production and neutrophilic inflammation in COPD patients. Allergy 2005; 60: 1361-1369.

43 Neumann S, Razen M, Habermehl P, et al. The non-neuronal cholinergic system in peripheral blood cells: effects of nicotinic and muscarinic receptor antagonists on phagocytosis, respiratory burst and migration. Life Sci 2007; 80: 2361-2364.

44 Caramori G, Di GC, Carlstedt I, et al. Mucin expression in peripheral airways of patients with chronic obstructive pulmonary disease. Histopathology 2004; 45: 477-484.

45 Sturgess J. The effect of isoprenaline and pilocarpine on (a) bronchial mucus-secreting tissue and (b) pancreas, salivary glands, heart, thymus, liver and spleen. Brit J Exp Pathol 1973; 54: 388-403.

46 Matsuba K, Thurlbeck WM. The number and dimensions of small airways in emphysematous lungs. Am J Pathol 1972; 67: 265-275.

47 Chua F, Laurent GJ. Neutrophil elastase: mediator of extracellular matrix destruction and accumulation. Proc Am Thorac Soc 2006; 3: $424-427$.
48 Taooka Y, Maeda A, Hiyama K, et al. Effects of neutrophil elastase inhibitor on bleomycin-induced pulmonary fibrosis in mice. Am J Respir Crit Care Med 1997; 156: 260-265.

49 Dunsmore SE, Roes J, Chua FJ, et al. Evidence that neutrophil elastase-deficient mice are resistant to bleomycin-induced fibrosis. Chest 2001; 120: 35S-36S.

50 Wollin L, Pieper MP. Tiotropium bromide exerts anti-inflammatory activity in a cigarette smoke mouse model of COPD. Pulm Pharmacol Ther 2010; 23: 345-354.

51 Barberà JA, Peinado VI, Santos S. Pulmonary hypertension in chronic obstructive pulmonary disease. Eur Respir J 2003; 21: 892-905.

52 Peinado VI, Pizarro S, Barbera JA. Pulmonary vascular involvement in COPD. Chest 2008; 134: 808-814.

53 Ferrer E, Peinado VI, Diez M, et al. Effects of cigarette smoke on endothelial function of pulmonary arteries in the guinea pig. Respir Res 2009; 10: 76.

54 Cirillo P, Golino P, Ragni M, et al. Activated platelets and leucocytes cooperatively stimulate smooth muscle cell proliferation and proto-oncogene expression via release of soluble growth factors. Cardiovasc Res 1999; 43: 210-218. 